\title{
SUPERNUMERARY HEADS OF BICEPS BRACHII WITH MEDIAN NERVE AND BRACHIAL VESSELS PASSING THROUGH THE THIRD HEAD
}

\author{
Sushil Kumar*, Ritwik Baidya.
}

Assistant Professor, Anatomy division, Department of radiology Weill Cornell Medicine, New York, USA.

\section{ABSTRACT}

A rare case of four-headed biceps brachii was observed during routine dissection on 60-year -old female old cadaver. The short head and long head had normal origin. The third head was originating from the humerus below the insertion of coracobrachialis, whereas fourth head was coming from the greater tubercle of the humerus. The median nerve and brachial vessels were passing through the third head. These variations are important because they could compress median nerve and brachial vessels.

KEY WORDS: Arm, Biceps Brachii, Brachial Vessels, Humerus, Median Nerve

Address for Correspondence: Dr. Sushil Kumar, Assistant Professor, Anatomy division, Department of radiology Weill Cornell Medicine, New York, USA. E-Mail: sushilbhu2001@yahoo.co.in

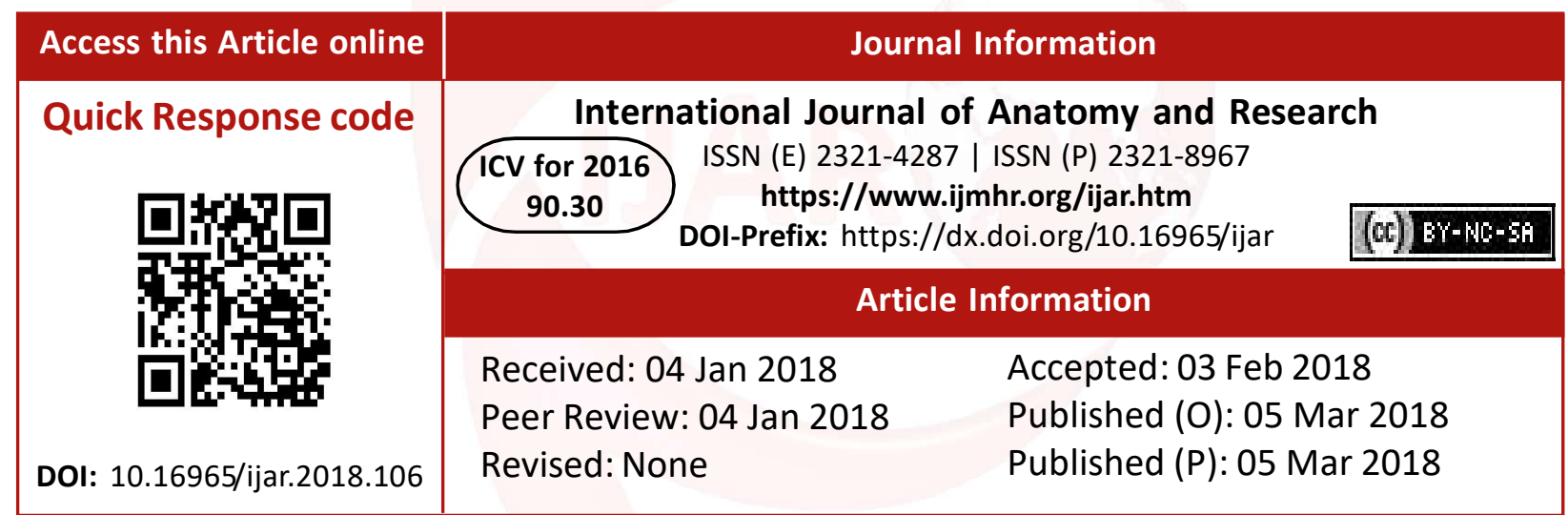

\section{INTRODUCTION}

Biceps brachii muscle is a muscle of the anterior compartment of the arm. Usually it has two heads - the short head and the long head. Variations up to seven heads have been reported. It is supplied by musculocutaneous nerve $[1,2]$. Median nerve runs posteromedial to the biceps brachii muscle. We present a case report in which we found a third and fourth head of the biceps brachii with the median nerve and the brachial artery passing through the third head. This variation is relatively rare.

\section{MATERIALS AND METHODS}

During routine dissection in the anatomy lab of Weill Cornell Medicine we encountered two supernumerary heads of the biceps brachii i.e. third and fourth heads in addition to the short and long heads. The third head was originating from anteromedial surface of the humerus below
Fig. 1: Showing the supernumerary heads of the biceps brachii.

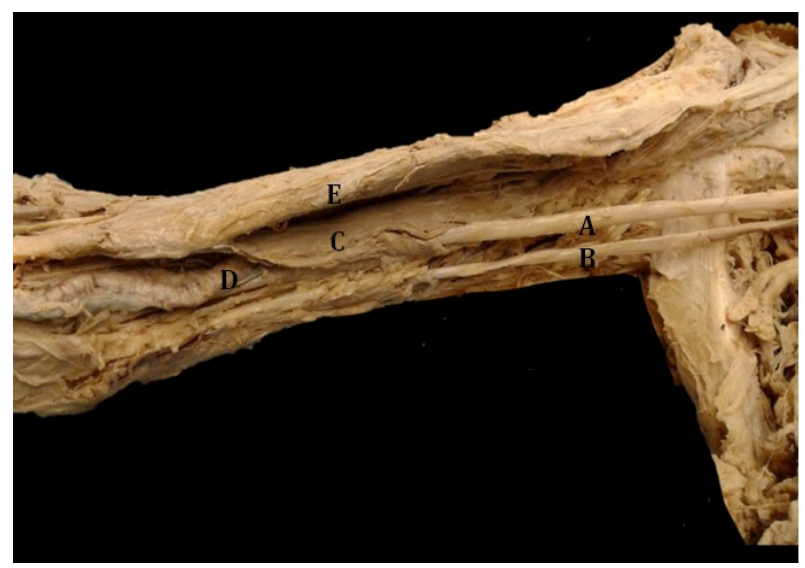

A - Median nerve, B - Ulnar nerve, $\mathrm{C}$ - Third head of the biceps brachii, D - Brachial vessels, E - short head of the biceps brachii.

the insertion of the coracobrachialis muscle and the fourth head were originating from the greater tubercle of the humerus. The length of third head and fourth head were $11.52 \mathrm{~cm}$ and 
$8.59 \mathrm{~cm}$ respectively. The circumference of the third head and the fourth head were $3.82 \mathrm{~cm}$ and $3.27 \mathrm{~cm}$ respectively. The third head was merging with the short head of the biceps brachii, whereas the fourth head was merging with long head of the biceps brachii. All heads were receiving its nerve supply from the musculocutaneous nerve. The median nerve and the brachial vessels were passing through the fourth head.

Fig. 2: Showing the supernumerary heads of the biceps brachii.

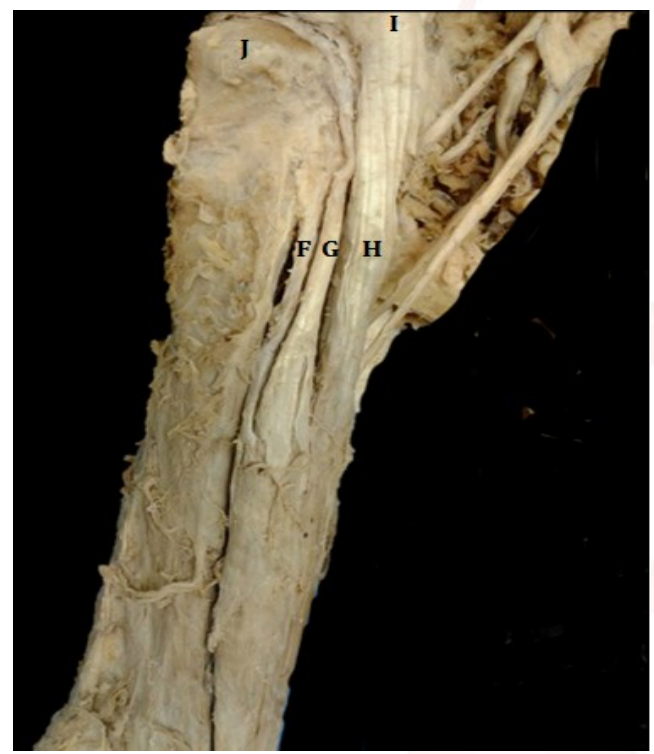

F - Fourth head of the biceps brachii, G - Long head of the biceps brachii, $\mathrm{H}$ - Short head of the biceps brachii, I - Coracoid process of the scapula, J - Greater tubercle of the humerus

\section{RESULTS AND DISCUSSION}

The biceps brachii muscle is a muscle of the anterior compartment of the arm with a short and a long head [1]. This muscle shows multiple variations in regard to the number of heads, with predominance in the male sex [3]. The most common variation is the presence of a third head followed by the presence of a fourth head. Racial variations have also been reported. Variations are more common in the black population than in the white population [3-5]. Biceps brachii receives its motor nerve supply from the musculocutaneous nerve and its blood supply via branches of the brachial vessels [1]. Usually, the median nerve and brachial vessels passes vertically down on the medial side of arm in between the biceps brachii and brachialis muscle. Nakatani et al reported a case in which biceps brachii had four heads bilaterally, the third head originating from the humerus just distal to the insertion of coracobrachialis muscle and a fourth head originating from the intertubercular sulcus. Both the heads inserted into the confluence of the biceps brachii. The third head gave off a muscle slip into the posterior fascia of the pronator teres, forming a tunnel. In his report, he mentioned that the median nerve and the brachial artery were passing through the tunnel [6]. Ongeti $K$ et al reported a case in which third head was passing over the median nerve. In this case median nerve was formed by the union of three contributions; two from lateral cord and one from medial cord [7]. A similar case was also reported by Deepika et al. [8] Danylo and Radovan reported a case in which the third head of biceps brachii originated from the coracocoid process along with the short head and inserted on to the humerus after enfolding the median nerve and brachial artery [9].

Satheesha et al reported a case in which median nerve was formed in the middle of the arm and then it passed through a tunnel in the third head of the biceps along with brachial artery [10].

In the present case, we observed four heads of the biceps brachii. Formation of the median nerve and musuculocutaneous nerve was normal. All the heads were receiving branches from the musculocutaneous nerve. The median nerve and the brachial vessels were seen deep to the short head of biceps brachii in the upper part of the arm. In the middle of the arm, they pierced through the third head and then coursed deep to it. Clinically, these variations are important as compression of the brachial artery may compromise the blood supply to the forearm and hand, in association with symptoms as a result of median nerve entrapment.

\section{Conflicts of Interests: None}

\section{REFERENCES}

[1]. Standring S. Gray's anatomy: The anatomical basis of clinical practice. $41^{\text {st }} \mathrm{Ed}$. London. Elsevier Ltd; 2016;824

[2]. Sinnatamby C. Last's anatomy: regional and applied. $12^{\text {th }}$ Ed. Edinburg. Churchill Livingstone; 2011;103

[3]. Bergman RA, Thompson SA, Afifi AK, Saadeh FA. Compendium of human anatomic variation: Text Catalog, Atlas and World Literature. Baltimore, Urban and Schwarzenberg; 1988;10-12. 
[4]. Asvat R, Candler P, and Sarmiento E E. High incidence of the third head of biceps brachii in South African populations. J anat. 1993;182(1):101-04.

[5]. Santo Neto H, Camilli JA, Andrade JC, Meciano Filho $J$, Marques MJ. On the incidence of the biceps brachii third head in Brazilian white and blacks. Ann anat.1998;180:69-71.

[6]. Nakatani T, Tanaka S, Mizukami S. Bilateral fourheaded biceps brachii muscles: the median nerve and brachial artery passing through a tunnel formed by a muscle slip from accessory head. Clin anat. 1998;11(3):209-12.

[7]. Ongeti K, Pulei A Ogeng'o J Saidi H. Unusual formation of the median nerve associated with the third head of biceps brachii. Clin anat.2012;25(8):961-2.
[8]. Deepika, Wadhwa S, Mahajan A and Mishra S. Rare inferolateral type of third head of biceps brachii coexisting with triple roots of median nerve. J human anat 201;1: 3.

[9]. Danylo Yershov, Radovan Hudak. Unusual variation of the biceps brachii with possible median nerve entrapment. Prague medical report 2015;116(2) :167-172.

[10].Satheesha Nayak, Vijay paul Samuel, Nagabhooshana Somayaji. Concurrent variations of median nerve, musculocutaneous nerve and biceps brachii muscle. Neuroanatomy. 2006;5:30-32.

How to cite this article:

Sushil Kumar, Ritwik Baidya. SUPERNUMERARY HEADS OF BICEPS BRACHII WITH MEDIAN NERVE AND BRACHIAL VESSELS PASSING THROUGH THE THIRD HEAD. Int J Anat Res 2018;6(1.3):50385040. DOI: $10.16965 /$ ijar.2018.106 